\title{
Estimating the iodine supplementation level to recommend for pregnant and breastfeeding women in Australia
}

\section{Dorothy E M Mackerras MPH, PhD, Chief Public Health Nutrition Advisor \\ Creswell J Eastman \\ MD, FRACP, FRCPA Vice Chairman ${ }^{2}$ \\ 1 Office of the Chief Scientist, Food Standards Australia New Zealand Canberra, ACT. \\ 2 International Council for the Control of lodine \\ Deficiency Disorders, \\ University of Sydney, Sydney, NSW. \\ dorothy.mackerras@ foodstandards.gov.au}

MJA 2012; 197: 238-242 doi: 10.5694/mjal2.10220
D ietary requirements for all nutrients are higher for women during pregnancy and lactation than when not pregnant or breastfeeding. During pregnancy, there is an increase of about $50 \%$ in maternal thyroxine production, a high rate of transfer of iodine and thyroxine from mother to fetus and increased maternal renal iodine clearance. ${ }^{1}$ Increased iodine requirements during breastfeeding allow for secretion of iodine in breastmilk. In Australia, the recommended iodine intake increases from $150 \mu \mathrm{g} /$ day for non-pregnant adult women to $220 \mu \mathrm{g} /$ day during pregnancy and $270 \mu \mathrm{g} /$ day while breastfeeding $^{2}$ (Box 1). The National Iodine Nutrition Survey conducted in 2003 and 2004 found that children living in south-eastern Australia were mildly iodine deficient. ${ }^{5}$ The results of several small contemporaneous studies of urinary iodine concentration in pregnant women were consistent with iodine insufficiency in pregnant women in the same states ${ }^{6-11}$ (Box 2).

Since October 2009, it has been mandatory to replace salt used in breadmaking with iodised salt, except in bread represented as organic. ${ }^{19}$ Food Standards Australia New Zealand (FSANZ) estimated that, in the general population of women aged 19-44 years, this strategy would increase mean iodine intake by $46 \mu \mathrm{g} /$ day and reduce the proportion of women with inadequate intakes from $59 \%$ to $9 \% .{ }^{19}$ Mean iodine intakes in pregnant and

\begin{abstract}
Objective: To identify a level of iodine supplementation to recommend for pregnant and breastfeeding women in Australia.

Design, setting and participants: Dietary modelling indicated that mandatory fortification of bread with iodine by replacing salt with iodised salt would still leave a gap in iodine intakes in pregnant and breastfeeding women in Australia. lodine shortfall was estimated by two separate methods: (i) analysis of data from published studies reporting mean urinary iodine concentrations in populations of Australian women who were pregnant or had given birth in the past 6 months; and (ii) modelling based on the postmandatory fortification iodine intake estimates calculated by Food Standards Australia New Zealand using food consumption reported by women aged 19-44 years who participated in the 1995 National Nutrition Survey.
\end{abstract}

Main outcome measure: Estimated level of daily supplementation required to provide sufficient iodine to result in a low proportion of pregnant and breastfeeding women having inadequate iodine intakes.

Results: Estimations from both data sources indicate that a supplement of $100-150 \mu \mathrm{g} /$ day would increase iodine intakes to a suitable extent in pregnant and breastfeeding women in Australia.

Conclusions: The final level of supplementation we recommend should be based on these calculations and other factors. There will be population subgroups for whom our general recommendation is not appropriate.

breastfeeding women were not calculated separately because there are too few of them in the dataset to allow separate estimation. Assuming that food consumption during pregnancy or lactation is the same as for the general population, FSANZ estimated that most of these women would still have inadequate intakes ${ }^{19}$ owing to their higher iodine requirements $(\operatorname{Box} 1){ }^{2}$

These concerns led to the National Health and Medical Research Council convening an expert group to consider if, and what level of, iodine supplementation should be recommended to pregnant and breastfeeding Australian women. ${ }^{20}$ As there is no nationally representative survey of iodine status in pregnant and breastfeeding women, the gap between the postfortification intake and the desirable intake was calculated using two different approaches and presented to the expert group. We describe these calculations and include more recent studies to update the information.

\section{Methods}

The two approaches we used to estimate iodine intake involved calculations based on (i) urine iodine concentrations and (ii) estimates of dietary intake. To this end, we

1 lodine intake recommendations for adult women

Source of recommendation and group of women

Estimated average requirement
Recommended dietary intake
Upper level of intake
Not pregnant or lactating, $\geqslant 19$ years

Pregnant, $\geqslant 19$ years

Lactating, $\geqslant 19$ years

Food and Agriculture Organization/World Health Organization ${ }^{3,4}$

Not pregnant or lactating

Pregnant and lactating
$100 \mu g / d a y$

$160 \mu g / d a y$

$190 \mu g / d a y$

Not defined

Not defined
$150 \mu g / d a y$

$220 \mu g / d a y$

$270 \mu g / d a y$

$150 \mu g / d a y$

$250 \mu g / d a y$
$1100 \mu g / d a y$

$1100 \mu g / d a y$

$1100 \mu g / d a y$ 
2 Estimated iodine intakes calculated from median urinary iodine concentrations reported in studies of pregnant or breastfeeding women and level of daily iodine supplementation needed to achieve an average intake of $250 \mu \mathrm{g} / \mathrm{day}$

\begin{tabular}{|c|c|c|c|c|c|c|}
\hline \multirow[b]{2}{*}{$\begin{array}{l}\text { Source and location of sampled } \\
\text { population }\end{array}$} & \multirow[b]{2}{*}{$\begin{array}{l}\text { Year of data } \\
\text { collection }\end{array}$} & \multirow[b]{2}{*}{$\begin{array}{l}\text { No. and details } \\
\text { of women }\end{array}$} & \multirow[b]{2}{*}{ Status } & \multirow[b]{2}{*}{$\begin{array}{l}\text { Median urine iodine } \\
\text { concentration } \\
(\mu g / L)\end{array}$} & \multicolumn{2}{|c|}{ lodine ( $\mu g /$ day) } \\
\hline & & & & & $\begin{array}{l}\text { Estimated } \\
\text { median } \\
\text { intake* }\end{array}$ & $\begin{array}{l}\text { Supplementation } \\
\text { required to raise median } \\
\text { intake to } 250 \mu \mathrm{g} / \mathrm{day}\end{array}$ \\
\hline \multicolumn{7}{|l|}{ Before fortification } \\
\hline Gunton et al, Northern Sydney, NSW ${ }^{6}$ & 1998-1999 & 81 & Pregnant & 104 & 166 & 84 \\
\hline Li et al, Western Sydney, NSW7 & 1998-1999 & 101 & Pregnant & 88 & 141 & 109 \\
\hline \multirow[t]{3}{*}{ Hamrosi et al, Melbourne, $\mathrm{VIC}^{9}$} & 1998-2001 & 227 white & Pregnant & 52 & 83 & 167 \\
\hline & & 263 Vietnamese & Pregnant & 58 & 93 & 157 \\
\hline & & $\begin{array}{l}262 \text { Indian/ } \\
\text { Sri Lankan }\end{array}$ & Pregnant & 61 & 97 & 153 \\
\hline Burgess et al, Hobart, TAS ${ }^{10}$ & $2000-2001$ & $\begin{array}{l}285 \text { hospital } \\
\text { antenatal care }\end{array}$ & Pregnant & 76 & 121 & 129 \\
\hline Chan et al, Sydney, NSW'2 & 2000 & 49 & $\begin{array}{l}\text { Breastfeeding 3-9 } \\
\text { days postpartum }\end{array}$ & 46 & na & na \\
\hline Travers et al, central coast, NSW"11 & 2004 & 815 & Pregnant & 85 & 136 & 114 \\
\hline \multirow[t]{2}{*}{ Mackerras et al, Darwin region, $N T^{13}$} & 2006-2007 & 24 Aboriginal teenagers & Pregnant & 49 & 78 & 172 \\
\hline & & $\begin{array}{l}11 \text { Aboriginal } \\
\text { teenagers }\end{array}$ & $\begin{array}{l}\text { Breastfeeding }^{\dagger} \\
<6 \text { months } \\
\text { postpartum }\end{array}$ & 39 & na & na \\
\hline Charlton et al, Wollongong, NSW ${ }^{14}$ & 2008 & 110 & Pregnant & 88 & 141 & 109 \\
\hline Nguyen et al, $A C T^{15}$ & Early 2009 & 100 & Pregnant & 62 & 99 & 151 \\
\hline Rahman et al, Gippsland, $\mathrm{VIC}^{16}$ & $\begin{array}{l}2009 \text { before } \\
\text { fortification }\end{array}$ & 24 & Pregnant & 96 & 153 & 97 \\
\hline \multicolumn{7}{|l|}{ After fortification } \\
\hline \multirow[t]{2}{*}{ Burgess et al, Hobart, TAS $^{10}$} & $2006^{\ddagger}$ & $\begin{array}{l}229 \text { hospital } \\
\text { antenatal care }\end{array}$ & Pregnant & 86 & 137 & 113 \\
\hline & $2003-2006^{\ddagger}$ & 288 primary health care & Pregnant & 81 & 129 & 121 \\
\hline Rahman et al, Gippsland, $\mathrm{VIC}^{16}$ & $\begin{array}{l}2009 \text { after } \\
\text { fortification to } \\
\text { February } 2010\end{array}$ & 62 & Pregnant & 95.5 & 153 & 97 \\
\hline \multirow[t]{2}{*}{ Axford et al, Illawarra, NSW ${ }^{17}$} & 2010 & $\begin{array}{l}27 \text { taking a } \\
\text { supplement } \\
\text { containing iodine }\end{array}$ & $\begin{array}{l}\text { Breastfeeding } 2.6 \\
\text { months postpartum }\end{array}$ & 206 & na & na \\
\hline & & $\begin{array}{l}33, \text { no iodine } \\
\text { supplements }\end{array}$ & Breastfeeding & 97 & na & na \\
\hline
\end{tabular}

ACT $=$ Australian Capital Territory. na $=$ Not applicable. NSW $=$ New South Wales. NT = Northern Territory. TAS $=$ Tasmania. VIC $=$ Victoria

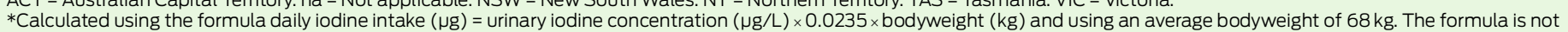

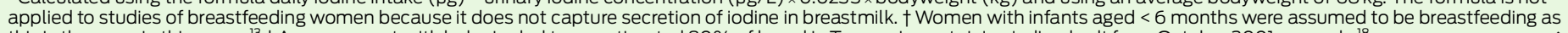
this is the norm in this group. ${ }^{13} \ddagger$ An agreement with bakeries led to an estimated $80 \%$ of bread in Tasmania containing iodised salt from October 2001 onwards. ${ }^{18}$

selected 11 studies conducted before and/or after fortification of bread with iodine, that reported the median urinary iodine concentration (MUIC) in Australian women who were pregnant or had given birth in the past 6 months. To estimate iodine intake from diet, we used the datafile compiled by FSANZ using food consumption data from the 1995 National Nutrition Survey (NNS) and subsequent iodine analyses of food.

\section{Urine iodine concentrations}

Except in breastfeeding women, urinary iodine excretion ( $\mu \mathrm{g} /$ day) accurately reflects recent iodine intake, with about $90 \%$ of dietary iodine appearing in the urine. ${ }^{1}$ The median urinary iodine concentration (MUIC) in a population, calculated from a single sample in each participant, is well accepted as a surrogate marker for population iodine intake because variations in hydration, although influential for individual iodine concentration measurements, generally even out when calculating the population median. The formula daily iodine intake $(\mu \mathrm{g})=$ urinary iodine concentration $(\mu \mathrm{g} / \mathrm{L}) \times 0.0235 \times$ bodyweight $(\mathrm{kg})$ is used for adults to estimate iodine intake from the iodine concen- tration in a spot urine sample. ${ }^{1}$ For example, an MUIC of $100 \mu \mathrm{g} / \mathrm{L}$ corresponds to an intake of $160 \mu \mathrm{g} /$ day for a bodyweight of $68 \mathrm{~kg}$. Conversely, an average population intake of $250 \mu \mathrm{g} /$ day would give an MUIC of about $156 \mu \mathrm{g} / \mathrm{L}$. This formula cannot be used to estimate iodine intake in breastfeeding women because it does not include the iodine content of breastmilk.

In addition to studies reporting MUIC data in pregnant Australian women $^{6-11}$ described in earlier reviews, 7,19,20 we identified four more recent studies ${ }^{13-16}$ and three reports on breastfeeding women (Box 2). ${ }^{13,12,17}$ One study (McElduff 


\section{Projected iodine intake of Australian women aged 19-44 years under different fortification and iodine} supplement scenarios

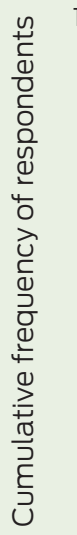$$
\begin{aligned}
& 100 \\
& 90 \\
& 80 \\
& 70 \\
& 60 \\
& 50 \\
& 40 \% \\
& 30 \% \\
& 20 \% \\
& 10 \%
\end{aligned}
$$

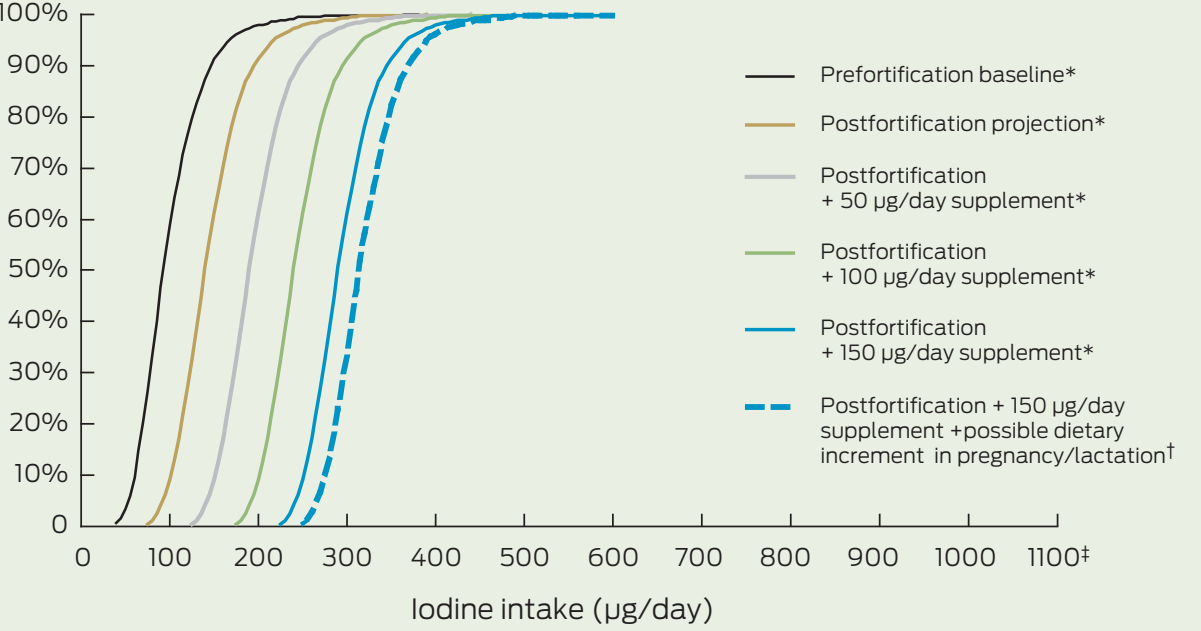

The upper level of intake recommended for adult Australian women is $1100 \mu \mathrm{g} / \mathrm{day}^{2}$

* Food consumption data from the 1995 National Nutrition Survey with Food Standards Australia New Zealand analytical iodine concentrations and estimated postfortification iodine concentration in bread. ${ }^{19}$

t Food-frequency data of key iodine-containing foods from a cohort study ${ }^{22}$ added to the $150 \mu \mathrm{g} / \mathrm{day}$ level of iodine supplementation. postfortification distribution of iodine intakes in Australian women with increasing increments of $50 \mu \mathrm{g} /$ day of iodine.

Because the data shown in the first five plots in Box 3 are not specifically for pregnant or breastfeeding women, the food-frequency data of key iodine-containing foods from a cohort study $^{22}$ were also considered.

\section{Results}

\section{Urine iodine concentrations}

Before fortification of bread with iodine, the estimated gap between iodine intake and the target ranged from $84-172 \mu \mathrm{g} /$ day (Box 2). Two studies were repeated after fortification. In Tasmania, after the implementation of a program that resulted in an estimated $80 \%$ of bread being made with iodised salt, ${ }^{18}$ the average gap was 113-121 $\mu \mathrm{g} /$ day compared with an average gap of $129 \mu \mathrm{g} /$ day before the program was implemented. ${ }^{10}$ In Gippsland, there was no difference before and after the enforcement date for national mandatory fortification. ${ }^{16}$ The three small studies in breastfeeding women ${ }^{12,13,17}$ had MUICs at the lower end of the MUIC range for pregnant women. of information about women's weight in the studies, we applied a weight of $68 \mathrm{~kg}$ to all studies of pregnant women to back-calculate iodine intake from the MUIC. This allows for some of the weight gain during pregnancy compared with the reference bodyweight of $61 \mathrm{~kg}$ used to derive nutrient reference values for nonpregnant Australian women (Box 1). ${ }^{2}$ For simplicity, we used a target dietary intake of $250 \mu \mathrm{g}$ (midway between the recommended daily intakes [RDIs] for pregnant and breastfeeding women) to calculate the gap in iodine intake in each study. The gap between calculated intake and the RDI of iodine for pregnant women $(220 \mu \mathrm{g})$ or breastfeeding women $(270 \mu \mathrm{g})$ can be determined by subtracting $30 \mu \mathrm{g}$ from, or adding $20 \mu \mathrm{g}$ to, respectively, the values shown in Box 2.

\section{Dietary estimates}

We used data on Australian women aged 19-44 years as a surrogate for food consumption of pregnant and breastfeeding women because the 1995 NNS data do not permit the iodine intakes of pregnant and breastfeeding women to be estimated directly.

We performed dietary calculations using the datafile of iodine intake estimates (excluding supplements and corrected for within-person variation) generated by FSANZ during their work on iodine fortification. ${ }^{19}$ The prefortification estimate was calculated by applying the iodine content of Australian food analysed between 2001 and 2005 to the reported food consumption in the NNS. The amount of iodine in bread after mandatory replacement of salt with iodised salt (using an average of $45 \mathrm{mg}$ iodine $/ \mathrm{kg}$ salt), allowing for $10 \%$ loss of iodine with baking, was calculated for each woman based on her reported bread consumption. ${ }^{19}$

Box 3 shows the prefortification and postfortification cumulative distribution of iodine intakes for the 2960 women aged 19-44 years in the NNS estimated by FSANZ, and allows the proportion of the population with intakes greater than and less than any iodine level to be read. For example, before fortification, about $60 \%$ of women had estimated iodine intakes below $100 \mu \mathrm{g} /$ day (therefore, about $40 \%$ had an intake greater than $100 \mu \mathrm{g} /$ day). Box 3 shows the progressive shift in the

\section{Dietary estimates}

We used the proportion with intakes less than the estimated average requirement (EAR; Box 1) to estimate the proportion of the population with inadequate iodine intakes. ${ }^{21}$ Supplementation with $100 \mu \mathrm{g}$ of iodine per day would result in the proportion of women with intakes below the EAR for pregnant women $(160 \mu \mathrm{g} /$ day) being essentially zero, and fewer than $10 \%$ of women having intakes below the EAR for lactating women $(190 \mu \mathrm{g} /$ day). Both of these values would be zero with supplementation with $150 \mu \mathrm{g}$ of iodine per day. Median iodine intakes would be $240 \mu \mathrm{g} /$ day with supplementation of $100 \mu \mathrm{g} /$ day and $290 \mu \mathrm{g} /$ day with supplementation of $150 \mu \mathrm{g} /$ day (Box 3). The highest iodine intake resulting from bread fortification plus supplementation with $150 \mu \mathrm{g}$ of iodine per day would be about $580 \mu \mathrm{g} /$ day (Box 3), which is well below the upper level of intake of 
$1100 \mu \mathrm{g} /$ day for adults in Australia and New Zealand ${ }^{2}$ (Box 1).

Food-frequency data of key iodinecontaining foods from a cohort study show that the intake of bread and dairy products is higher in pregnant and postpartum women, and this might increase iodine intake by about $20 \mu \mathrm{g} /$ day compared with that of nonpregnant women. ${ }^{22}$ We added this to the $150 \mu \mathrm{g} /$ day supplementation level in Box 3 (sixth plot) as an approximation for iodine intakes in pregnant and lactating women.

\section{Discussion}

Results from analyses using urinary iodine concentration data or dietary modelling support a conclusion that iodine intake was inadequate in the locations studied before and after bread fortification. Despite using different data sources and assumptions, both methods identify a gap in iodine intake in the range of 100 $150 \mu \mathrm{g} /$ day. We believe that this is the first time that these types of complementary data have been used to derive an estimate of the level of iodine supplementation that should be recommended.

There are no urinary iodine concentration studies of pregnant or breastfeeding women in Western Australia and Queensland where the MUIC is between 100 and $150 \mu \mathrm{g} / \mathrm{L}$ in children. ${ }^{5}$ Studies such as those from Tasmania ${ }^{10,23}$ indicate that the MUIC in children provides an estimate of the MUIC in adults. MUIC in the range of $100-149 \mu \mathrm{g} / \mathrm{L}$, while sufficient in children, indicates insufficiency in pregnant women. ${ }^{4}$ It is therefore possible that pregnant women in Western Australia and Queensland have insufficient iodine intake.

Most of the urinary concentration studies were in opportunistic samples of women. The large variation in MUIC among them may relate to differences in dietary intake, geographic influences such as the iodide content of local water, time of day when the samples were collected owing to diurnal variation in hydration, different stages of pregnancy of the women in the samples, or may have come about because some studies were conducted in tertiary hospitals while others were community-based.
The urinary concentration data provide the basis for an estimation of the average iodine intake target for the population only. The dietary estimate allows the population iodine intake distribution to be compared with criteria for both adequacy and excessive intakes. Although advice about iodine supplementation is directed at individuals, the amount of iodine in the supplement does not need to equal the RDI. The purpose of this type of recommendation is to improve population nutrient status so that only a low proportion of the population would have inadequate intakes. ${ }^{24}$ As shown in Box 3, the median iodine intake of the population is higher than the RDI and a small proportion will have intakes below the EAR with supplementation of 100-150 $\mu$ g per day.

There are few data about the dietary intakes of pregnant and breastfeeding women in Australia. Food frequency data in the 2003 Australian Longitudinal Study on Women's Health showed similar consumption of key iodinecontaining foods for both pregnant women and women after giving birth and these were slightly higher than consumption by non-pregnant women in the same cohort. ${ }^{22}$ Therefore, we believe that, in the absence of better data, the information from urinary concentration studies of pregnant women can be reasonably extrapolated to breastfeeding women to estimate their iodine intakes, and that the dietary data from the general adult female population do not substantially underestimate iodine intake in the groups of interest. Data on iodine intakes, urinary concentrations and supplement use are being collected in the 2011-2013 Australian Health Survey. ${ }^{25}$ The new data will show whether population iodine intake has changed substantially since 1995. This will allow some of the strategies aimed at improving iodine intake in the population to be assessed. Pregnant and breastfeeding women are not being oversampled which limits evaluation in these groups. A minimal effect on MUIC among pregnant women was reported after fortification. ${ }^{10,16}$ MUIC excludes additional iodine transferred to the fetus which may partly explain these results. The Tasmanian iodine fortification program achieved a smaller proportion of fortified bread than national regulation. ${ }^{10}$ The result from Gippsland ${ }^{16}$ is difficult to interpret without knowing when the samples were obtained and when bread fortification actually started during the year-long transition before the enforcement date in October 2009. Further information about current iodine status of pregnant and lactating women would be desirable.

Our calculations do not yield a single "correct" answer, but show the range of the gap in iodine intake. In addition to these numerical results (Box 2), other factors affect the supplement dose that should be recommended. A committee or organisation needs to consider what weighting should be given to each of the various non-representative studies, extrapolation of results in pregnant women to breastfeeding women and what prevalence of inadequate intake would be tolerable in the population. Other factors include whether a single recommendation to cover both groups could be made, whether the dose should be inflated to allow for missed days in supplement consumption, safety over the period of intended use for those with the highest dietary intakes, and whether it is possible to recommend a dosage that is currently available in the marketplace. A further consideration is how to factor in the uncertainty in the reference values (eg, the Food and Agriculture Organization/World Health Organization has the same recommendation for both groups [Box 1]) and the consequences of making or not making a recommendation.

In summary, two approaches using different types of data to estimate iodine intakes indicate that, after mandatory fortification of bread, supplementation in the range $100-150 \mu \mathrm{g}$ of iodine per day would increase population iodine intakes in pregnant and breastfeeding Australian women to the levels recommended. The final recommendation depends on a range of other factors as well as these calculations. As with any population-level recommendation, there are subgroups for whom the general recommendation is not appropriate; in this case, women with established thyroid disorders.

Acknowledgements: We acknowledge permission from Food Standards Australia New Zealand to use the iodine intake datafile. Julie Boorman did the dietary modelling 
for the prefortification and postfortification iodine estimates that formed the basis for the current analysis.

Competing interests: The work for this study was done while we were both members of the National Health and Medical Research Council Expert Panel on lodine

Supplementation for Pregnant and Lactating women.

Received 3 Feb 2012, accepted 12 Jun 2012.

1 Zimmermann MB. lodine deficiency. Endocr Rev 2009; 30: 376-408.

2 National Health and Medical Research Council and New Zealand Ministry of Health. Nutrient reference values for Australia and New Zealand Introduction. Canberra: NHMRC, 2006. http://www.nrv.gov.au/ introduction.htm (accessed Feb 2011).

3 Food and Agriculture Organization of the United Nations, World Health Organization. Human vitamin and mineral requirements. Report of a Joint FAO/WHO Expert Consultation. Rome: FAO/ WHO, 2002. http://www.fao.org/DOCREP/004/ Y2809E/y2809e00.htm (accessed Mar 2011).

4 WHO Secretariat, Andersson M, de Benoist B Delange F, Zupan J. Prevention and control of iodine deficiency in pregnant and lactating women and in children less than 2-years-old: conclusions and recommendations of the Technical Consultation. Public Health Nutr 2007; 10:1606-1611.

5 Li M, Eastman CJ, Waite KV, et al. Are Australian children iodine deficient? Results of the Australian National lodine Nutrition Study. Med J Aust 2006; 184: 165-169.

6 Gunton JE, Hams G, Fiegert M, McElduff A. lodine deficiency in ambulatory participants at a Sydney teaching hospital: is Australia truly iodine replete? Med J Aust 1999; 171: 467-470.

7 Li M, Ma G, Boyages SC, Eastman CJ. Reemergence of iodine deficiency in Australia. Asia Pac J Clin Nutr 2001; 10: 200-203.

8 McElduff A, McElduff P, Gunton JE, et al. Neonatal thyroid-stimulating hormone concentrations in northern Sydney: further indications of mild iodine deficiency? Med J Aust 2002; 176: 317-320.

9 Hamrosi MA, Wallace EM, Riley MD. lodine status in pregnant women living in Melbourne differs by ethnic group. Asia Pac J Clin Nutr 2005; 14: 27-31.

10 Burgess JR, Seal JA, Stilwell GM, et al. A case for universal salt iodisation to correct iodine deficiency in pregnancy: another salutary lesson from Tasmania. Med J Aust 2007; 186: 574-576.

11 Travers CA, Guttikonda K, Norton CA, et al. lodine status in pregnant women and their newborns: are our babies at risk of iodine deficiency? Med 」 Aust 2006; 184: 617-620.

12 Chan SS, Hams G, Wiley V, et al. Postpartum maternal iodine status and the relationship to neonatal thyroid function. Thyroid 2003; 13: 873-876.

13 Mackerras DE, Singh GR, Eastman CJ. lodine status of Aboriginal teenagers in the Darwin region before mandatory iodine fortification of bread. Med J Aust 2011; 194: 126-130.

14 Charlton KE, Gemming L, Yeatman H, Ma G. Suboptimal iodine status of Australian pregnan women reflects poor knowledge and practices related to iodine nutrition. Nutrition 2010; 26 : 963-968.

15 Nguyen B, Baker D, Southcott E, et al. lodine deficiency in pregnant women in the ACT. ANZ J Obstet Gynaecol 2010; 50: 539-542. doi: 10.11ו1/ 1479-828X.2010.01239.x.

16 Rahman A, Savige GS, Deacon NJ, et al. Urinary iodine deficiency in Gippsland pregnant women: the failure of bread fortification? Med J Aust 2011; 194: 240-243.

17 Axford S, Charlton K, Yeatman H, Ma G. Improved odine status in breastfeeding women following mandatory fortification. Aust N Z J Public Health 2011; 35: 579-580.
18 Seal J. The makings of the Tasmanian (interim) iodine supplementation program 2001-2004. In: Richards PAC, Stewart JC, editors. Goitre monitor: the history of iodine deficiency disorders in Tasmania. South Launceston, Tas: Myola House of Publishing, 2007: 208.

19 Food Standards Australia New Zealand. Proposal P1003. Mandatory iodine fortification for Australia. Approval report. Canberra: FSANZ, 2008. http:// www.foodstandards.gov.au/_srcfiles/AppR P1003_Mandatory_lodine_Fortification Aust\%20AppR.pdf (accessed Feb 2011).

20 National Health and Medical Research Council. lodine supplementation for pregnant and breastfeeding women. NHMRC public statement. Canberra: NHMRC, 2010. http:// www.nhmrc.gov.au/_files_nhmrc/file/ publications/synopses/new45_statement.pdf (accessed Feb 2011)

21 National Research Council. Dietary reference intakes: applications in dietary planning. Washington, DC: The National Academies Press, 2003. http://www.nap.edu/catalog.php?record id=10609 (accessed Jun 2012)

22 Mackerras D, Powers J, Boorman J, et al. Estimating the impact of mandatory fortification of bread with iodine on pregnant and postpartum women. J Epidemiol Community Health 2011; 65: 1118-1122.

23 Seal JA, Doyle Z, Burgess JR, et al. Iodine status of Tasmanians following voluntary fortification of bread with iodine. Med J Aust 2007; 186: 69-71.

24 Cockell KA, Miller DC, Lowell H. Application of the Dietary Reference Intakes in developing a recommendation for pregnancy iron supplements in Canada. Am J Clin Nutr 2009; 90: 1023-1028.

25 Australian Bureau of Statistics. Australian health survey. http://www.abs.gov.au/websitedbs/ D3310114.nsf/Home/Australian+Health+Survey? OpenDocument (accessed Jan 2012).

\section{Stamps of greatness}

\section{Jan Ingenhousz (1730-1799)}

INGENHOUSZ was born on 8 December 1730 in

Breda, Holland, and studied medicine at the University of Leuven, where he received his degree in 1752.

Although a physician, he was primarily interested in the natural sciences.

He discovered photosynthesis and cellular respiration in plants and published his findings in 1779.

For a time he practised medicine in Holland and in England before joining the Court of Austria to inoculate the royal family against smallpox, as two of the empress's children had died of the disease.

Robert and Daniel Sutton in England in 1760 and Gatti in France in 1769 had been successfully using variolation - the deliberate inoculation with the smallpox virus that was widely practised before the era of vaccination as prophylaxis.

At the urging of Voltaire in 1768, Empress Catherine and Archduke Paul of Russia had been inoculated by Dimsdale. That same year Ingenhousz inoculated three children in the royal household in Austria after preliminary experiments on 200 children in Vienna. Subsequently, the success of Jenner's experiments swept variolation from the field.

In later years Ingenhousz returned to England and was elected to the Fellowship of the Royal Society.
He died in Bowood, near London, on 7 September 1799, and was postally honoured by the Netherlands in 1941 as a great physician.

AMA Gazette 1978; Jan

\section{Jacobus Ludovicus Schroeder van der Kolk (1797-1862)}

VAN DER KOLK was born in Leeuwarden, the Netherlands, on 14 March 1797 and studied medicine at the University of Groningen. He was an honours student, earning two gold medals and graduating about 1817. After practising in the country for a short time at Hoorn, he became physician to a hospital in Amsterdam. Appointed as Professor of Anatomy and Physiology at the University of Utrecht in 1827, he introduced microscopic and experimental techniques in the study of histologic anatomy. Particularly interested in the contemporary treatment of the mentally ill, he introduced better nursing and medical care in the insane asylums, developed the psychiatric approach and studied the anatomy of the brain of the mentally deficient.

He died in Utrecht, the Netherlands, on 1 May 1862. He was postally honoured by the Netherlands in 1960 on a stamp to commemorate Mental Health year.

AMA Gazette 1977; Nov.

John Roche, Moss Vale, NSW 
Research

Pfizer Viagra 